\title{
1. Introduction to the Handbook on Gender in Asia
}

Shirlena Huang and Kanchana N. Ruwanpura

\section{INTRODUCTION}

Why privilege gender in a volume on Asia? The answer, as evident in the chapters in this volume, is that gender continues to be a fundamental factor in the way lives of individuals, families and societies across Asia are organized on multiple fronts and spaces. While modernization and globalization have generated changes and challenges to cultural traditions and practices, the persistence and durability of gender ideals and norms surrounding men's and women's roles across the life cycle still characterize much of Asia. Patriarchal attitudes ensure that gender inequality remains high in many parts of Asia (McKinsey Global Institute, 2018).

Much research from feminist and gender perspectives, however, has clearly demonstrated that we cannot homogenize men as privileged and empowered vis-à-vis women as victims and lacking agency even under this scenario. Rather than simply providing more evidence to support this observation, the chapters in this volume identify gaps in existing scholarship on gender issues in Asia, in which work remains limited. Through a major literature review, each chapter provides an overview of the intellectual developments and contributions of the topic that is covered in the chapter, before turning to empirical discussions drawing from the author's own research. While many chapters employ qualitative methods, several use quantitative analyses. Most chapters end with proposals for a research agenda intended to move lines of enquiry on the topic forwards productively.

Significantly, this is not only a multi-disciplinary compendium of scholarship in gender studies on Asia but one in which Asian voices are clearly represented - not only in the case studies discussed, but also because authors in and from Asia figure strongly. Notably, several authors in this volume do not necessarily publish in English. Many feminists have called for increased transnational dialogues and conversations that include academics from beyond the English-speaking global North (Nagar, 2002; Raghuram, 2019). This volume is thus also to some extent a means to bring together perspectives from scholars based in Asia and beyond to critically examine, from a gender perspective, existing and emerging issues relating to five broad themes: the 'Theory and Practice' of researching in Asia; 'Gender, Ageing and Health'; 'Gender and Labour'; 'Gendered Migrations and Mobilities'; and 'Gender at the Margins'. It is hoped that this volume can help to move gender scholars working in/on the region, towards 'developing new Asian feminist and gendered discourses that make sense of the local empirical realities of Asia on the one hand, while connecting and speaking 
to the broader global discourse of feminism on the other' (Huang, 2014: 24). The various contributions in each of the five parts are discussed next.

\section{GENDER IN ASIA: THEORY AND PRACTICE}

Despite claims of post-coloniality in recent years, there is still a specific geography and hierarchy of academic knowledge production that informs the lived reality of writing and doing research into gender in Asia, as noted in different ways by the chapters in this first part of the book. All three chapters are reflexive pieces by authors writing on Asia, but from different social (and physical) locations inside and outside Asia. Each highlights the differential gendered and other power relations that have to be negotiated, not just in the field, but also within the broader institutional, societal and cultural contexts within which they research. Each author also alerts the reader to strategies that can help researchers negotiate the constraints that are faced.

Anindita Datta, a feminist geographer, highlights the complex entanglements of patriarchy, race, caste, class and global North-global South politics that have privileged and reproduced colonial and masculinist ways of knowing that result in systemic sexism in Indian academic institutions (Chapter 2). She forwards Deniz Kandiyoti's (1988) notion of the 'patriarchal bargain', wherein women comply with restrictive gender roles and patriarchal expectations in order to maximize their life options. Datta argues that this patriarchal culture has also been internalized within the Indian academy, resulting in a parallel acquiescence to the privileging of masculinist, positivist paradigms over critical social theory within mainstream human geography in order to survive. This inevitably limits the scope of research and recognition for those working in the sub-fields of gender geography and feminist geographies in India. She also highlights the challenges of writing from the global South for international publications, when international (read: Western) review processes seek to maintain their hegemony on knowledge even of the non-Western world.

The next two chapters shift the focus to the challenges of conducting research in the field. Wai-man Tang's chapter provides a reflexive account of his experience as a Chinese male ethnographer conducting his $\mathrm{PhD}$ research with Nepali drug users in Hong Kong (Chapter 3). Tang's account reveals how it is presumptuous to assume that his gender (heterosexual male), race (dominant racial group in Hong Kong) and position as a researcher/teacher conducting research in his own country would mean that he could naturally adopt a hegemonic masculine identity to establish power when conducting his fieldwork, as per existing drug studies done by male researchers. His account highlights the importance of being willing to overcome the uncertainty of the research process by practising a variety of gender identities (ranging, for example, from a tougher masculinity to a more vulnerable femininity). Maddy Thompson similarly reveals the complexity of field identities that researchers must negotiate, even from a position of apparent privilege as a white Western young woman postgraduate researcher in Asia (Chapter 4). In this sense, her chapter also reinforces the arguments Datta makes in her chapter about the privileging of the global North. As 
a feminist scholar, Thompson emphasizes how researchers from the global North have a responsibility to carry out ethical and care-full research in Asia. Yet, she also recognizes how privilege can be a complex issue: her privilege is tempered by her gender and her youth, and to some extent her whiteness, which acts to heighten her visibility and, hence, vulnerability in her field site.

All three chapters in this part also draw out strategies that researchers can use to negotiate their 'out of placeness' as researchers and sensitize themselves to power relations in studying gender in Asia - whether it is allowing for flexible gendered performances in the field or the importance of mentoring and obligation to share knowledge - 'embracing' what Moss (2019: 1) has described as 'an ethos of care and mentoring'. There is also a call for those who are more experienced (and privileged) to work collaboratively 'within paradigms that are collective, feminist and not fast-paced' (this volume, Datta, Chapter 2) to overcome the triple bind of gender, race and location for the less privileged.

\section{GENDER, AGEING AND HEALTH}

The first thematic part focuses on ageing as a gendered phenomenon. Asia is at the forefront of the global phenomenon of population ageing. It is expected to experience a doubling of its older population aged 60 or over by 2050, with numbers rising to about 1.3 billion from the current level (United Nations, Population Division, 2017). Older women are said to be not only more vulnerable to poverty than older men, but women outlive men by several years. Asia's growing ageing population thus raises very specific concerns faced by men and women, not only as elderly themselves needing care, and for women, also as unpaid caregivers of other elderly. Yet, how ageing is experienced as a gendered phenomenon in Asia has been poorly studied and under-theorized. The chapters in this part seek to address this lacuna.

Drawing on nationally representative survey data, Bussarawan Teerawichitchainan and John Knodel's chapter provides a gendered analysis of well-being among older men and women in Myanmar, Vietnam and Thailand (Chapter 5). Their findings concerning old-age well-being indicators (including health status and receipt of personal care, economic well-being, and social connectedness) suggest a need to reassess the focus that academic and policy research has given to female disadvantages in old age. Rather than stark differences, their analysis reveals more nuanced gender differences in old-age well-being between men and women in these three Southeast Asian countries. As such, they advocate for a more balanced perspective that examines gender as only one of the intersecting markers of old-age vulnerability so that both male and female disadvantages can be addressed. Yi Yang also draws on large-scale quantitative datasets to examine the notion of the feminization of old age and well-being in China (Chapter 6). While she found significant gender differences between men and women with regard to aspects such as ability to perform activities of daily living, cognitive impairment, and emotional distress - with women having higher levels, especially as they aged - her findings (like Teerawichitchainan and 
Knodel's) also suggest that gender differences are more complex than a consistent pattern of women's disadvantages vis-à-vis their male counterparts. Yang argues that scholarship should recognize that men face problems in old age too. These chapters highlight how studies adopting a gender perspective in understanding ageing and well-being are needed not just in quantitative terms, but also in terms of qualitative studies examining the gendered experiences of ageing at the level of individuals and families.

The next three chapters in this part turn from well-being in old age to how eldercare is being configured in different parts of Asia. In discussing the case of Japan, the first Asian country to become an ageing society and currently having the highest rate of ageing in the world, Ruri Ito and Mie Morikawa discuss how the state introduced Long-term Care Insurance in 2000 and subsequently opened the labour market to migrant eldercare workers in 2016 to support informal (primarily family-based, and often female-based) eldercare (Chapter 7). They also highlight the differences in the gendered expectations placed on adult children for eldercare in Japanese and Korean society versus those in China, Singapore and Thailand. Their chapter emphasizes the need to consider the changing dynamics of gender relations within the interplay of formal and informal eldercare, given the 'compressed modernity' that characterizes many countries in Asia. In contrast to Ito and Morikawa's focus on eldercare within Japan itself, Lan-hung Nora Chiang and Elsie Seckyee Ho turn our attention to how families provide eldercare from a distance with the growing significance of transnational families in Asia, and how it has reconfigured traditional gendered norms and conventional ways of family-based parent care (Chapter 8). They examine the case of Taiwanese-Chinese immigrants in Australia and New Zealand where adult children are providing care to their aged parents living in Taiwan. While Chinese traditions of filial piety remain strong, their findings suggest that it is not just daughters and daughters-in-law who are expected to provide care for 'left-behind' elderly parents. Instead, migrant children do their very best to share in eldercare work regardless of gender, either by returning to Taiwan or bringing their parents to Australia and New Zealand for extended periods. This indicates how transnational contexts have enabled a shift in eldercare practices from 'gender-specific' to relatively 'gender-flexible'. Paul Statham puts a slightly different spin on the transnationalization of eldercare in his case study of Thailand as a destination for foreign male migrants seeking sex, girlfriends, wives and carers (Chapter 9). He examines cross-border marriages between Thai women and older Western men who move to Thailand to unpack the gendered negotiated exchanges of care for the men (and to some extent the women) and material rewards (primarily for the women) in these unions. While these exchanges can lead to relative financial security for some of the women, Statham's analysis highlights how these relationships can exert a great cost on the women's psychological well-being over time.

Issues of health and well-being matter not only because they raise issues of the burden of care in old age, but because they begin when people are much younger. In particular, women tend to take on and endure the main burden of juggling roles and responsibilities on multiple fronts while being employed, yet suffer from exclusions 
and inequalities in the productive sphere, as the contributions in the section on gender and labour evince.

\section{GENDER AND LABOUR}

The International Labour Organization's (ILO, 2018) flagship report for Asia registers how labour has been behind Asia's growth trajectory where the region's workers have directly or indirectly been part of its recent growth dynamism. The ILO report also draws our attention to the paucity of decent work in the Asian region. As such, the purpose of this part of the volume is to go beyond regional data and trends to appreciate what it means to be labouring in the region. Labour, as these chapters show, is not an empty trope. It is both temporally and spatially inflected by various social hierarchies, including class, caste, gender and sexual orientation. Hence, to understand labour in Asia, we also need to appreciate the intersections between gender and labour. The chapters in this part thus interrogate the relationship between these two dimensions, along with various gender labour regimes within various national contexts of Asia. In bringing the Asian region to focus, we also move across bounded imaginaries to include Asian parts of the bordering Middle East, namely the Asian part of Turkey, thereby disrupting boundaries and binaries in multiple ways. The chapters also demonstrate how the gender division between productive/ reproductive spheres produces a series of exclusions and divisions that result from many types of work.

The feminization of labour is a theme explored in two different regions of Asia. Ayşe Arslan's contribution draws out how processes of informalization and feminization of labour are not merely linked to each other but also to neoliberal transformations and patriarchal gender regimes (Chapter 10). She does this by examining the export-oriented sector. While the number of women in this sector in Turkey has increased, the informalization of labour within it has been possible because of the ways in which gender norms within the country have been mobilized to legitimize these processes. In contrast, Cynthia M. Caron (Chapter 11) explores transformations in the agricultural sector in South Asia to discern similar threads. She points out that, with deepening vertical integration, there has also been a quiet revolution that both solidifies and destabilizes gender relations and norms in various nodes of the value chain, within the agricultural sector. She uses both descriptive statistical data and qualitative data to show that, as women are increasingly drawn into the agricultural value chain, they help disrupt conventional masculinized understandings of farming as being occupied by men. This is the seeming quiet revolution. Yet, women farmers are more likely to be poorly resourced and their access to relevant agricultural inputs and technology remains scanty. The paucity and lapses in systematic documentation of women's control to and control over the agricultural means of production results in gendered inequities perpetuating or taking different forms.

The next two chapters interrogate the theme of newness in gender identity formations in their contributions for Vietnam and Pakistan, respectively. Sarah Turner, 
Ammar Adenwala and Celia Zuberec (Chapter 12) outline how street vending is dominated by women in Southeast Asia, and their migrant status, ethnicity and gender norms interconnect to both create opportunities and marginalize street vending women simultaneously. Drawing upon stereotypically 'feminine' traits (such as sweetness, patience and malleability) allows these Southeast Asian women to negotiate their public presence via street vending effectively. Within this seemingly paradoxical scenario, increasingly, a salient pattern is the violence perpetrated against the women in a bid to remove them from public spaces. This is bound up with the quest to create world class cities, where mobilizing imaginings of modern and aspirational 'worlding' cities is done at the cost of dispossessing those that use the urban space to eke a living (Roy, 2011). Using the experiences of street vending women in Hanoi, Vietnam, the authors illustrate how women draw upon various novel strategies to negotiate this everyday violence - and how, in the process, claim their rights to the city. The authors contend that city 'upgrading' may be done more effectively if all urban dwellers are incorporated into imaginary visions of urban futures. Imaginary futures of modernity and the modernization of Pakistan is the theme underlying Sara Shroff's contribution, where working women are being mediated as economic 'game changers' for the country's growth process (Chapter 13). In the quest to forge a new Pakistan, the identity of its women's identity is reconfigured in ways that underline the contradictions involved in the new growth phase of Asia. Pakistani women's visibility and economic viability is increasingly emphasized for the nation's well-being and capitalist ventures (Ruwanpura and Hughes, 2017). Yet, Shroff outlines how Pakistani women are crafted concurrently as possessing the ability to be socially productive through sexual respectability and modesty, while also undermining the patriarchal status quo. She overviews the literature to argue that tropes of morality and modesty are pivotal in re-presenting and rebranding Pakistan as pious, progressive and peaceful - and thus safe to be an integral part of Asia's buoyant capitalist growth trajectory.

Visions of branding nations, whether Pakistan or India, however, always cast to the margins and underplay the lives of those that have made countries pulse and flourish, even though this process has been uneven for those countries and especially those who labour (ILO, 2018). In India, domestic workers have provided the dynamism needed for households and families to live, work and contribute to its socio-economic landscape. India works because of its informal sector and precarious workers, which has held to be the case historically as well as in more contemporary times. Lauren Wilks draws together key historical, sociological and anthropological literature to delineate the long history of domestic work in India, where caste and class structures have determined these relations through colonialism to the present day (Chapter 14). She points out that, although the landscape of domestic work has evolved and is changing, its dogged persistence suggests the need for further exploration. In particular, there is a paucity of appreciating how domestic workers commute, as they often no longer are live-in workers (Ray and Qayum, 2010). More importantly, as the gig economy grows and platform work is on the rise, the apps developed to facilitate employers to hire domestic workers also enable them to do so on the basis of social 
markers (religion, race, ethnicity, age, gender, etc.). This suggests that modern technology is used to perpetuate prejudices and discriminatory behaviour.

These chapters have highlighted how gendered labour is constructed within the different contexts. They have noted the disposability or lack thereof, of how work travels between the 'inside' and 'outside' worlds, and how women workers perceive, make sense of, respond and experience work at different sites. In particular, the chapters have tried to connect the dots between men's and women's worlds of labour and gendered labour regimes. As the next part examining migrations and mobilities in Asia shows, the endurance of gendered norms also characterizes the lives and experiences of men and women as they move for work, retirement and other reasons.

\section{GENDERED MIGRATIONS AND MOBILITIES}

Several of the chapters discussed so far have provided some indication of the importance of migrations and mobilities in Asia, in terms of the transnational movements of migrant care labour and family members to provide eldercare. Indeed, Asia has the largest number of international migrants of any continent, as both a sending and receiving region from within Asia as well as beyond. These flows are not only varied, but also distinctly gendered patterns. While much of the research on Asia as a site and source of migration has tended to focus on lower-skilled labour migration, the chapters in this part reflect on a range of other migrant flows, as a means highlighting the complexity of these movements and their gendered implications - a point that Parvati Raghuram and Gunjan Sondhi make in their chapter, which examines highly skilled migration in the knowledge sector within, from and to Asia (Chapter 15).

Raghuram and Sondhi note that while women form a large part of skilled migrant flows, they have had little place not only in the imaginaries of Asian gendered migration, but also in academic research. Their review of the literature, however, makes it clear that not only do skills and gender influence mobility, but also that mobility shapes skills and gender. Their chapter also highlights the need to examine the intersections between the productive and reproductive spheres. Raghuram and Sondhi show, for example, that while highly skilled women are deemed more 'marketable' as potential partners, their moves as the lead/primary migrant can challenge and disrupt men's normative roles in both productive and reproductive spheres. We need more research to understand how the mobility of the highly skilled challenges existing gender hierarchies and norms. What happens to skilled women migrants post-retirement? In her chapter, Menusha De Silva proposes an integration of the lifecourse perspective and intersectionality to examine how age, migration and other social identities come together to shape the later-life mobilities of skilled migrants (Chapter 16). She presents the case study of two Sri Lankan skilled migrant women living in the UK and unpacks how personal aspirations, family obligations, community relations and state policies intersect and lead to opportunities and impediments throughout their lifecourse. Even as they negotiate these (dis)advantages, their gen- 
dered care needs and obligations remain central to the ways in which they fulfil their retirement aspirations.

Hyunok Lee's chapter on Vietnamese women migrating to South Korea as foreign brides also takes a lifecourse perspective (Chapter 17). On the one hand, the women's migration decisions throughout their lifecourse reflect the gendered nature of socio-economic changes in both Vietnam's industrialization and Korea's post-industrialization periods. On the other hand, Lee's analysis highlights how the narratives of these women cannot be understood just within a single typology of migration, a point also made by De Silva with regard to later-life migrations (also see Chapter 20 for a discussion of the biopolitics of migrant classification). They are not simply either marriage migrants or labour migrants. As they move within Vietnam and then internationally to Korea, the women make multiple transitions between productive and reproductive roles and spheres to provide for their natal and spousal families, either as wage workers and/or unpaid care labour at home. Hiroki Igarashi introduces the phenomenon of kyoiku-ijū in which Japanese women accompany their children overseas (in this case, to Malaysia) for the latter's international schooling (Chapter 18). Like Lee's, Igarashi's analysis also highlights how the narratives of the women cannot be understood within a single typology of migration. Instead, the women can be understood as pursuing both education(al) and lifestyle migration, based on a twofold gendered project to accumulate global and regional cultural capital for their children, and self-growth for themselves.

Also within the context of transnational families - in this case, first-generation immigrant Coorg women (Kodavathees) living in urban Karnataka, Singapore and Sydney - Bittiandra Chand Somaiah's chapter includes a discussion of immigrant mothering, an area that has not received much systematic attention in Asia (Chapter 19). She reminds us that transnational/immigrant parenting is often a site constantly under moral scrutiny by the parents' home community, often linked to the resilience of gender ideals and norms surrounding motherhood in Asia. She highlights how an extended moral community of co-responsibility is at play in the way (im)migrant mothers encourage both relational citizenship practices and homely belonging within their children, as they aspire to raise model citizens in global cities. The final chapter in this part, by Sallie Yea, intensifies our attention on the emotional and moral dimensions of transnational migration, as expressed within gendered norms and processes in Asia (Chapter 20). Arguing that the return stage of migration is a relatively neglected research area, Yea focuses on the case of male and female return migrants to the Philippines. She analyses the ways gendered moral frames intersect with migration to produce cultural frames through which the negative emotions associated with failed migration can be understood and articulated.

The various chapters demonstrate how migration in Asia cannot be discussed without consideration of the family. As Asis et al. (2019: 24) have observed, migration 'casts light on the family as a stakeholder situated between the global and the local, between the market and the state, and as an important safety net for families in origin and destination countries'. In Asia, the growing cache of work on the Asian transnational family challenges us to go beyond normative notions of dominant 
(Western) constructions of the family as nuclear and the idealized gendered roles within it. Contributions in the next and final part of this volume explore how the endurance of gendered norms often results in sites of exclusion for women in Asia.

\section{GENDER AT THE MARGINS}

In Domosh and Seager's (2001) discerning intervention, they try to make sense of their Euro-American world by providing coverage of women's invisibility from the Victorian period to contemporary times. They foreground the ways in which gendered contestations have shaped our private and public worlds alike, yet the multiple social lives that animate our world do not necessarily get the visibility they deserve. It is these spaces which are explored in this part of the volume.

Kyoko Kusakabe outlines how women's migrant workers' invisible experiences are so desperate that what gets attention speaks to our gendered worlds as much as does the silence (Chapter 21). As with many of the chapters in the previous part, Kusakabe notes how discussions of transnational families tend to focus on long distance mothering or the situation of children left behind but neglect the issue of care arrangements for children who travel with their parents - often, lone mothers, who become migrant workers. Her short intervention provides an overview of the Mekong river region, where permeable borders between neighbouring Thailand, Myanmar, Laos and Cambodia and unequal growth have led to notable migration and mobility. Hosting more than three million migrant workers from its neighbouring countries, Thailand has had to adopt a special registration system to document these workers. Yet, undocumented migrant workers and their children continue to seep through its borders. Currently, 300,000-400,000 migrant children are estimated to reside in Thailand because the Thai government recognizes both the presence and importance of migrant workers, and, according to UN Women (2017), it has extended its education policy to include pre-school for stateless and migrant children. These policies and statistics, however, are one side to the story. The relational aspect to childcare and the web of interdependence it draws upon is that which has tended to be neglected or downplayed in the literature. Women migrant workers who move with their children no longer may have their grandparents or kin to draw upon, and so must embrace other tactics for childcare. Kusakabe's analysis draws our attention to the troubling, difficult and unstable circumstances within which migrant women workers make their decisions.

The challenging circumstances women inhabit and have to negotiate in their daily lives also tend to be hidden from view and marginalized in the lives of those who live in the continuum of violence. The next two chapters focus our attention on women living at the edge of violent conflict and societies, and underline that treating civil and social violence as separate domains does not capture the scales of gendered violence. Elaine Ho argues that internally displaced people are growing and numerous (estimated at 36 million, globally), but their neglect means that we fail to appreciate how displaced women's identities are shaped in the spatial domains of 
home, work and the public sphere in distinct ways (Chapter 22). Their difficulties are never fully comprehended in critical humanitarianism, human security and state security debates. She uses the case of Kachin women internally displaced between the China-Myanmar border to highlight the difficulties and challenges they face as women, mothers and citizens. Smita Ramnarain (Chapter 23) furthers the call for us to be attentive to the fallacy propagated, theoretically and empirically, when we treat social and civil conflict as distinct. Using examples from trafficked and widowed women in Nepal, she outlines how violence against women needs to be understood as interconnected domains. She argues that a siloed approach towards violence faced by women obscures and elides structural forms of exclusion that accumulate over time and importantly, speaks to all contexts, including where war and extraordinary violence may not be the everyday yet everyday violence prevails. It is the neglect of these marginal spaces that evades the necessary scrutiny to appreciate the stubborn persistence of gendered norms.

Turning to the realm of student activism, notably on the radar again, enables us to better grasp the tenacity of inequities in gender relations. Students are increasingly at the forefront in the fight for social justice and in challenging the incursion of neoliberal logics into their everyday, educational establishments, including in Asia (Jeffrey, 2010). Asha L. Abeyasekera starts her chapter by overviewing recent student resistance and movements in Asia (Chapter 24). While these uprisings are less spectacular than student movements in the 1960s, she notes how they should not be marginalized but better appreciated. Using the case of Sri Lanka, she also argues that student activism - where analysed - has neglected the gender dimension and the role of women students in these mass movements. This gap is particularly telling, as women have increasingly entered higher education in greater numbers, yet their involvement in multiple spheres of education life has been neglected. While Abeyasekera illustrates how women are dubbed over to make space for men's voices in student activist movements, she also gleans hope through the multiple roles that young women take on in these spaces - and hence unsettle gendered norms.

These contributions, through their mappings of multiple and conflictual spaces, show how the possibilities for creating awareness together with political and social change can be enacted, as slow as they may seem. They have traced for us how women's presence and strength is as enduring as gendered norms may be, and it is through this fortitude that transformations can come about, starting from the margins.

\section{A CONCLUDING WORD}

As editors, we hope that through the case studies presented, as well as identifying gaps in the current research and possible agendas for future research on issues in Asia related to the five themes covered, this multidisciplinary collection will make a useful intervention in the understanding of the gendered experiences of both men and women, whether in terms of the issues to be studied, methodological considerations and methods undertaken, or the theorising of gender in Asia and elsewhere. 
Although the volume was finalised just before the COVID-19 crisis, the interventions in the volume are particularly worth ruminating on against the backdrop of the current global pandemic, wherein gender, ethnic, racial, environmental and structural inequalities in the world are becoming painfully and searingly obvious. How we craft a different world moving forward will need to be attentive to these schisms and fractures of the global polity.

\section{REFERENCES}

Asis, Maruja M.B., Piper, N. and Raghuram, Parvati (2019), 'From Asia to the world: "Regional" contributions to global migration research', Revue Europeenne des Migrations Internationales, 35 (1), 13-37.

Domosh, Mona and Seager, Joni (2001), Putting Women in Place: Feminist Geographers Make Sense of the World. New York: Guilford Publications.

Huang, Shirlena (2014), 'Developing a view from within: Researching women's mobilities in/ out of Asia', Asian Journal of Women's Studies, 20 (1), 8-30.

ILO (2018), Asia-Pacific Employment and Social Outlook: Advancing Decent Work for Sustainable Development. Bangkok: Regional Economic and Social Analysis Unit, ILO

Jeffrey, Craig (2010), 'Geographies of children and youth I: Eroding maps of life', Progress in Human Geography, 34 (4), 496-505.

Kandiyoti, Deniz (1988), 'Bargaining with patriarchy', Gender and Society, 2 (3), 274-290.

McKinsey Global Institute (2018), The Power of Parity: Advancing Women's Equality in Asia Pacific. https://www.mckinsey.com/featured-insights/gender-equality/the-power-of-parity -advancing-womens-equality-in-asia-pacific (accessed 6 December 2019).

Moss, Pamela (2019), 'Pursuing a feminist ethos of care and the practice of mentoring', Gender, Place \& Culture, 26 (1), 1-2.

Nagar, Richa (2002), 'Footloose researchers, "travelling" theories, and the politics of transnational feminist praxis', Gender, Place \& Culture, 9 (2), 179-186.

Raghuram, Parvati (2019), 'Race and feminist care ethics: Intersectionality as method', Gender, Place \& Culture. DOI: doi.org/10.1080/0966369X.2019.1567471.

Ray, Raka, and Qayum, Seemin (2010), Cultures of Servitude: Modernity, Domesticity, and Class in India. New Delhi: Oxford University Press.

Roy, Ananya (2011), 'The blockade of the world-class city: Dialectical images of Indian urbanism', in A. Roy and A. Ong (eds), Worlding Cities. Chichester, UK and Malden, MA, USA: Wiley-Blackwell, pp. 259-278.

Ruwanpura, Kanchana and Hughes, Alex (2016) 'Empowered spaces? Management articulations of gendered spaces in apparel factories in Karachi, Pakistan', Gender, Place and Culture, 23 (9), 1270-1285.

United Nations, Population Division (2017), World Population Ageing 2017: Highlights. New York: United Nations. https://www.un.org/en/development/desa/population/publications/ pdf/ageing/WPA2017_Highlights.pdf (accessed 6 December 2019).

UN Women (2017), Women Migrant Workers in the ASEAN Economic Community. Jakarta: The ASEAN Secretariat. 